\title{
Impact of Personality Factors on Consumer Buying Behaviour Towards Textile Materials in South Eastern Nigeria
}

\author{
Marcus Garvey Orji ${ }^{1}$, Bello Sabo ${ }^{1}$, Muktar Y. Abubakar ${ }^{1}$, Abubakar D. Usman ${ }^{2}$ \\ ${ }^{1}$ Department of Business Administration, Faculty of Administration, Ahmadu Bello University, Zaria, Nigeria \\ ${ }^{2}$ Department of Local Government and Development Studies, Faculty of Administration, Ahmadu Bello University, Zaria, Nigeria
}

Email address:

orjimarcusgarvey@yahoo.com (M. G. Orji), myabubakar@me.com (M. Y. Abubakar), biousman@yahoo.com (A. D. Usman)

\section{To cite this article:}

Marcus Garvey Orji, Bello Sabo, Muktar Y. Abubakar, Abubakar. D. Usman. Impact of Personality Factors on Consumer Buying Behaviour Towards Textile Materials in South Eastern Nigeria. International Journal of Business and Economics Research.

Vol. 6, No. 1, 2017, pp. 7-18. doi: 10.11648/j.ijber.20170601.12

Received: October 31, 2016; Accepted: February 24, 2017; Published: April 17, 2017

\begin{abstract}
The objective of this study is to assess the impact of personality factors on consumer buying behavior towards textile materials in South Eastern Nigeria. Five personality factors of social character, compliance, aggressiveness, ethnocentrism and dogmatism form the basis for the hypotheses, Survey method of data collection was used in the course of the research. Statistical tools which include mean, standard deviations, and multiple regressions were applied in data analysis and hypotheses testing. The results from the analysis revealed that there is a significant effect of social character, compliance, aggressiveness, ethnocentrism on consumer buying behavior of textile materials in South Eastern Nigeria, whereas dogmatism has no such significant effect. The finding of this study leads to conclusion and lends further support to the assumptions that personality is a highly relevant explanatory concept for the examination of consumption of goods and services. Therefore the study recommended among others, that producers and marketers of textile materials in South Eastern Nigeria should design them in line with the personality factors identified, as this will go a long way in the patronage of made-in-Nigeria textiles and contribute to economic growth and development of Nigeria. Also, considering the social character of the people in this region, marketers should target their strategies on convincing the social influencers within any age grade, as their purchase decisions will go a long way in commanding the brand acceptance of each product. Marketers of textile materials in this region should consider the use of celebrities to promote their products, especially during festivals by designing textile materials that will add glamour to such festivals.
\end{abstract}

Keywords: Personality, Consumer Buying Behaviour, Textile Materials, South Eastern Nigeria

\section{Introduction}

An individual or a consumer is always influenced by his culture, subculture, social class, reference groups, family, personality, and his psychological factors. Thus, understanding purchasing behaviour of Nigerian buyers, especially the Igbos is critical to marketers. A strong understanding of such buying behavior will help shed light on what is important to them and also suggest the important influences on their decision making. Considering Kotler \& Armstrong's [1] definition of marketing as a social and managerial process by which individuals and groups obtain what they need and want by creating and exchanging value with others, therefore, consumer value should be the foundation for all marketing activities and deserves the attention of every marketing researcher.

Consumer buying behaviour refers to the buying behaviour of the ultimate consumer, and many other factors and characteristics that influence the individual in what he is and in his decision making process, shopping habits, purchasing behaviors, the brands he buys or the retailers he patronizes. A purchase decision is the result of each and every one of these factors. Thus, consumer behaviour might be the mental, emotional and physical activities that people engage in when selecting, purchasing, using and disposing of products and services so as to satisfy needs and desires (Keng, Tran \& Le 
thi,[2], Pinki, [3]).

Consumer behaviour is more than just the physical purchase of products but rather covers a wide range of activities from the problem awareness stage through postpurchase behavior, ideas formulation, or experiences to satisfy their needs and desires. It entails the study of people's needs, motivations, and thought processes used in choosing one product over another and the patterns of purchasing different goods and services. In essence, it is concerned with how individuals and groups select, buy, use, and dispose of goods (Haliru, [4], Yakup [5]).

Consumers purchase products to reflect their personality. The type of house, clothes, furniture, appliances, automobiles, jewelry people buy indeed reflect their personalities. Ali, Babak \& Seied [6] simply described personality as the kind of behaviour that people have in front of the others and their reactions which are shown in the society. Also, Sagini \&Haridas [7] defined Personality as what a person actually is. It also includes his thoughts, feelings and behaviour, and that this overt behaviour is due to his interaction with the society and other fellow human beings.

Each and every individual is having his own personality and behaviour pattern which is different in every sense. They maintained that consumers buying behaviour is greatly influenced by this personality traits. Personality is a person's consistent pattern of responses. It is an internal structure in which experience and behaviour are related in an orderly way [7].

One individual is different from others not only in the physical aspects, but also in personality types. It is one of the factors that influence one's behavior in the market place. What a consumer purchases, when and how he or she purchases are influenced by his personality types [8].

Personality therefore, in our context is all the inherent characteristics that explain the way an average Igbo man or woman is, and how that influences his/her social environment and buying behavior towards textile materials.

In order to persuade the consumers, marketers have to study the consumer behavior. Thus, Marketers of various products search for potential personality traits that their target market might reveal, and aim their advertising campaigns at enhancing the personality of the target group, for example; feel the Rev, Proud to be different "Be Important", "Be successful", are adverts aimed at enhancing personality [9]. In marketing textile materials, there are different attributes that might enhance personality and attract the attention or admiration of consumers like the Igbos of South Eastern Nigeria. These attributes include colours, designs and quality of fabrics. Among the Igbos, personality and attitude play a vital role in consumer decision making especially in the purchase of textile materials. The attitude of Igbo consumers towards textile materials is relatively cognitive and affective. Cognitive here relates to beliefs or disbelief, whereas affective relates to feeling of negative or positive nature involving some emotional context [1].

The belief of many Nigerians are that made in Nigeria textiles are of inferior quality and costly on one hand, and on the other it is a sign of achievement to use foreign made rather than Made in Nigeria textile materials [9]. Based on this belief the patronage of made in Nigeria textile materials is premised on condition of cost, and prestige. Cost here implies that those who cannot afford the foreign costly one patronize the local textile materials, because it is cheaper. Prestige here implies that the consumer needs to be identified when he wears a particular type of material. This occurs when people want to be identified with an object, person or events. For instance printing the picture of some one very important on a textile material will evoke impulse that results to purchases by his/her admirers or sycophants. Also a group of people could decide to adopt a particular colour or print of textile materials as a means of identification with friends or an association popularly called "Aso-ebi" as many age grades do in South Eastern Nigeria [9].

The personality factors that affect consumer buying behaviours which are our study's explanatory variables are social character, compliance, aggressiveness, ethnocentrism and dogmatism [8] [10]. For instance, under the social character, the main issue is social class. Every society like the Igbos possesses some form of social class which is important to marketers, because the buying behavior of people in a given social class always appear the same. Also the compliance individuals are easily influenced by other consumers as their desire to move towards others, while aggressive consumers desire to excel in all they do and can easily influence others. Although there are many factors affecting attitude and intentions to purchase textile materials, personality is very important, and should be taken into consideration by researchers. Because it is generally believed in Nigeria that the way someone dresses is the way he or she would be addressed [9]. Thus, a marketer and consumer are affected by behavioral intentions such as how to make consumer buy and pay more, developing his brand preference, make them tell others good things about the product or brand [11].

There is therefore is need to examine the consequences of personality factors controlled behaviour on the manipulation of marketing variables with a view to making possible profit. It is in the light of this that this study seeks to assess personality factors as determinants of consumer buying behavior with particular emphasis on textile materials in South Eastern Nigeria.

\subsection{Statement of the Problem}

In this era of globalization, the competition among firms producing the same goods and services has intensified and the consumer, who is considered the principal focal point in a modern business approach, becomes more and more important. Since marketing starts with the needs of the consumer and ends with need satisfaction, then everything revolves around the consumer and thus the study of consumer behavior becomes a necessity (Khan, [12]; Yakup [5]). Thus, the postulate of the famous English Philosopher and Political Economist, Adam Smith, that consumption is 
the antithesis of production (Awa, Kalu \& Awara, [13]) holds firmly in sway if the marketing strategist rolls out marketing programmes that recognize the personality differences, however minor, of the target audiences, perhaps in terms of their thought about, and use of products. Different factors might influence consumers to switch from one brand to another if it doesn't match their personality. Since consumers are the focal point it is therefore essential to satisfy them [13].

Marketers have to contend with the issue of how to determine when and how personality is an important factor in buying decisions among consumers. This also applies to the Igbo speaking consumers of South Eastern Nigeria. There is the need to analyze the different personality traits and factors which may be dominant in South Eastern Nigeria in buying textile materials. Doing this will help producers and marketers in decision making towards designing textile materials in line with the personality of the people, thereby attracting more patronage of Made in Nigeria textiles and discourage importation. And the major components of personality factors that influence consumer behaviours which marketers have to contend with; are social character, compliance, aggressiveness, ethnocentrism, and dogmatism [8]. For instance, under social character, who and what influence the buying behavior of a particular social class? Who and why some consumers move towards and against others in terms of compliance and aggressiveness? Also who and why the display of rigidity in terms of dogmatism?

There has been a general belief that all societies exhibit some form of personality stratification, whereby individuals can be assigned a specific personality status. Based on Neofreudian and trait theories [9] it is necessary to assess how personality concepts can aid in the determination of decision making, and understanding of consumer's buying behavior especially in a society like South Eastern Nigeria.

Several studies have been conducted on personality factors and traits in relation to the product, culture and brand preferences, these include, Tan, Foo, \& Kwek [14], Matzler, Faullant, Renzl \& Leiter [15], Ade, Costas, Garcia-Godos, Iglesias, Llerena, Ramic, Carraher, Pratt, Brown, \& Woodside [16], Ranjbarian \& Kia [17], Murat [11], Mehmet [18], Johari \& Hee [19], Sarker et al [8], Ghorbani \& Mousavi [20], Ali, Babak \& Seied [6], Sagini \& Haridas [7]. But to the best of our knowledge none of the existing researches has considered the influence of personality factors on the buying behavior of Igbos in the South Eastern Nigeria towards textile materials. This study fills this gap. There is a need for marketers and producers of textile materials to understand the personality traits of the Igbos, so as to enable them decide a strategy that will effectively reach them. Lack of understanding of the influence of personality factors on designing, and consumption of textile materials is a major problem in the patronage of locally produced textile materials in Nigeria, particularly the South East. This study provides a clarification of the personality issues involved in the marketing of textile materials in the South East of Nigeria.

\subsection{Research Questions}

On the whole, this study will attempt to provide answers to pertinent questions such as;

I Does social character affect consumer's buying behavior of textile materials in South Eastern Nigeria?

II To what extent does compliance affect consumer's buying behaviour of textile materials in South Eastern Nigeria?

IIIIs there any significant effect of aggressiveness on consumer's buying behavior of textile materials in South Eastern Nigeria?

IVTo what extent does ethnocentrism affect consumer's buying behaviour of textile materials in South Eastern Nigeria?

V Does dogmatism affect consumer's buying behaviour of textile materials in South Eastern Nigeria?

\subsection{Objectives of the Study}

The main objective of this study is to assess the impact of personality factors on consumer buying behavior towards textile materials in South Eastern Nigeria. To achieve this, the following secondary objectives would also be considered;

I Identify the effect of social character on consumer's buying behavior of textile materials in South Eastern Nigeria.

II Examine if compliance affect consumer's buying behaviour of textile materials in South Eastern Nigeria.

IIIDetermine whether aggressiveness affect consumer's buying behavior of textile materials in South Eastern Nigeria.

IVAssess whether ethnocentrism affect consumer's buying behaviour of textile materials in South Eastern Nigeria.

$\mathrm{V}$ Investigate if dogmatism affect consumer's buying behaviour of textile materials in South Eastern Nigeria.

\subsection{Research Hypotheses}

The following null hypothetical assumptions have been postulated for validations in order to help achieve the objectives of the study;

$\mathrm{H}_{0 \mathrm{i}}$. There is no significant effect of social character on consumer's buying behavior of textile materials in South Eastern Nigeria.

$\mathrm{H}_{0 \mathrm{ii}}$. There is no significant effect of compliance on consumer's buying behaviour of textile materials in South Eastern Nigeria.

$\mathrm{H}_{0 \mathrm{iii}}$. There is no significant effect of aggressiveness on consumer's buying behavior of textile materials in South Eastern Nigeria.

$\mathrm{H}_{0 \mathrm{iv}}$. There is no significant effect of ethnocentrism on consumer's buying behaviour of textile materials in South Eastern Nigeria.

$\mathrm{H}_{0 \mathrm{v}}$. There is no significant effect of dogmatism on consumer's buying behaviour of textile materials in South Eastern Nigeria. 


\subsection{Scope of the Study}

The issues that have been raised and discussed in this study are based on how marketing managers and producers of textile materials can use the consumer behaviour research findings on personality as a factor to enhance their performance and effectiveness in producing and marketing textile materials. It covers the five Eastern States of Abia, Anambra, Ebonyi, Enugu and Imo, which are mostly Igbo speaking people of Nigeria. The study covered the period of 11years from 2004 to 2014 . This period witnessed the full establishment of democracy in Nigeria, and increased purchasing power of the people. Democracy enhanced more even distribution of wealth, especially the middle class income earners, which had influenced their consumption level and pattern. This is because income level and life style are among the major attributes or boosters of personality.

\section{Literature Review}

\subsection{Conceptual Framework}

\subsubsection{Personality}

Our sense of self is shaped by our inherited characteristics and by influences in our social environment. The process of growing up; such as the impact of our early family life and the part of country we live has a significant part to play in our identity [21]. In any one person, certain personality traits dominate as a result of which people are labeled as sociable, aggressive, complaint, aloof, friendly, charismatic or obnoxious, or typically described as having one or more characteristics such as, compliant, compulsiveness, ethnocentrism, dogmatism, authoritarianism, introversion, extroversion, aggressiveness, social character, ectomorphic, endomorphic, mesomorphic, and competitiveness [9]. Personality is a concept which accounts for the apparent consistencies and regularities of behavior over time and across a variety of situations. According to Pinki [22], personality is the set of traits and specific characteristics of each individual. It is the product of the interaction of psychological and physiological characteristics of the individual and results in consistence behaviors. It materializes into some traits such as confidence, sociability, autonomy, charisma, ambition, openness to others, shyness, curiosity, and adaptability. Personality has been understood as a unique way in which traits, attitudes, and aptitudes are organized in an individual and this draws attention to the ways in which individuals differ from one another through the peculiar configuration of traits.

Each consumer is unique in terms of his or her ambitiousness, competitiveness, conservatism degree of extroversion and so on [8].

Personality can be defined as all distinctive and unique behaviors of individual. The word "Person" comes from "Persona" (Latin) meaning mask people wore according to their roles in theatre [23] [11]. So, its basic conception is consistent to what a person plays as a social role in the society or in another word, person's general character that shows to those around him/her, and good looking characteristics accepted by people of the world [24]. Thus, we hear the sentence (Marcus is a Gentleman) in daily conversations for instance, these concepts are out of the field of scientific psychology because these descriptions of the characters, in fact, depend on the quality and type of behavior of Marcus [24].

According to Ali et al [6], personality sometimes is used for showy and prominent characteristics and adjectives of a person so that in some cases, he/she may be considered as a coward or a gallant or even an angry person. In the other words we can describe personality as the kind of behaviour that people have in front of others and their reactions which are shown in the society [25]. Ali et al [6] uniquely classified people into two in terms of personality. The first one is called the group of the wisdom owners and the other one is called the group of the non wisdom owners, and that each one should be known with their own characteristics and they must be treated as good as it is possible The wisdom owners apply reasoning and cautions in their behaviours, while for non wisdom owners anything goes.

Personality can be also defined as organized set of physical, intellectual and spiritual and characteristics possessed by a person that makes him different from others. It can also be stated that personality is a kind of established, consistent and distinctive relation, including reactions, with others [26] [27]. Personality may also be viewed as consisting of stable characteristics that explain why a person behaves in a particular way. For instance, independence, conscientiousness, agreeableness and self-control would be examples of these personality characteristics [21].

But, Kottler \& Keller [28] were of the view that Personality mean a set of distinguishing human psychological traits that lead to relatively consistent and enduring responses to environmental stimuli. They described it in terms of such traits as self confidence, dominance, autonomy, deference, sociability, defensiveness and adaptability. But we do not entirely agree with them, because they did not take cognizance of the physiological dimension, because the physical appearance of a person also goes a long way in influencing responses to environmental stimuli. According to Dursun [29], personality is set of fixed features and behavioral patterns that help individual suit his environments. Personality causes people to evaluate everything around them by means of their personal traits. Sometimes, people in shopping centers say "This cloth does not reflect my personality" or "This reflects my character" [30]

Uztuğ [31], Çetin \& Beceren [27], Schiffman \& Kanuk [10], and Onu et al [9] postulated that;

I Personality makes an individual different from others

II Personality is consistent and permanent (a consistent pattern of behavior that endures over time in response to an event or environment)

IIIPersonality may change (response to the dynamism of environmental and social milieu, via nurture).

This study aligns itself with these postulations. This is 
because the focus of our study, the Igbos have similar characteristics that suite these postulations, viz a viz, the Igbos are unique people and different from others. They are known to be from the breeds of indigenous South Eastern Nigeria any where in the World. They have consistent and permanent behavior towards money and purchasing of goods and services. They are commonly referred to as- 'People who love money so much'[9], and their behavior may change due to some environmental factors like some being influenced by other cultures after staying outside Igbo land for a long period of time. These authors' definitions of personality do not encompass the two major approaches to the study of personality; the nomothetic and idiographic approach. Each of these authors defined personality based on a particular theoretical assumption of either biological influences or environmental/social influences. Whereas our definition encompass both biological and environmental/social influences. Thus, by our working definition, personality is all the inherent characteristics that explain the way an average individual (Igbo man or woman) is, and how that influences his/her social or environmental milieu and buying behavior over time.

Ali et al [6] uniquely classified people into two in terms of personality; the wisdom owners and the non wisdom owners, and that each one should be known with his/her own characteristics and must be treated as good as it is possible. This study is however, of the opinion that, people should rather be grouped into 'the rational and the non-rational' The rational people are those who see their world and environment the way they are and try to fine tune their strategy to adapt and survive. They combine intelligence with the realities of the prevailing environmental circumstances. While the non-rational people are those who see their world and environment the way it is and want it to come to terms with their beliefs or opinions.

\subsubsection{Consumer and Consumer Behaviour}

Consumer is the one who ultimately utilizes the goods and services produced, while customer is a person, company or other entity which patronizes another person, company, or other entity regularly. A consumer may be a customer, while a customer may not be a consumer, because he/she may not be buying for his or her uses. But in studying consumer behavior, customers are also generally referred to as consumers, because whether they are the buyers or users, there is an exchange or transfer from one person to another for needs satisfaction [5]. Thus, consumer behaviour is the study of the processes involved when individuals or groups select, purchase, use or dispose of products, services, ideas or experiences to satisfy needs and desires [31].

Buying behaviour is the decision processes and acts of people involved in buying and using products, where as, consumer buying behaviour refers to the buying behaviour of the ultimate consumer [22]. Also, according to Mehmet [18], consumer buying behavior involves purchasing and other consumption related activities of people engaging in the exchange process. It has also been described as the mental, emotional and physical activities that people engage in when selecting, purchasing, using and disposing of products and services so as to satisfy needs and desires. Behavior of consumer is motivated or purposive. The behavior is directed towards the goal of obtaining products or other resources. It is the activities of people engaged in actual and potential use of market items-whether products, services, retail environments or ideas [8]. The better the firm understands its consumers like the Igbos, the more likely it becomes successful in the marketplace. Knowledge of consumer behavior would render immense help for planning and implementing marketing strategies in a competitive environment like Nigeria [24].

\subsection{Measurement of Personality}

While understanding what personality is, it is also important to understand how it is organized, what functions it performs, how it can be measured to help a marketer to successfully combat competition. There are two basic determinants of personality; heredity and past interactions with the environment. Psychologists like Feldman [32], Alkahtani, Abu-Jarad, Sulaiman \& Nikbin [33] indeed have termed these determinants as "nature" and "nurture". But Mullins [21], and Orji [24], use the word idiographic and nomothetic techniques or approaches to classify them.

According to Alkahtani et al [33], nature stands for the belief that personality is shaped largely by heredity, that is to say, much of our personality is inherited in birth. They suggest that as much as $50 \%$ of our personality is genetically determined. On the other hand, nurture stands for the belief that personality is shaped mainly by life experiences, environmental and social milieu especially those from the cradle. Indeed, there is no accurate answer to the issue of how much nature and nurture affect and shape our personalities. However, our genetics make up sets of lower and upper limits for our personalities and our life experiences will determine where within that range we will fall [33]. The idiographic approach involves studying a single individual as a complete, complex, interacting system, and the understanding of the societal context in which the person lives. Idiographic approaches are concerned with understanding the uniqueness of individuals and development of self concepts. The approach regard personality development as a process that is open to change, and also regard individuals as responding to the environment and people around them, and see the dynamics of the interactions as playing a critical part in shaping personality. Thus, the measurement of traits is seen as largely inappropriate in that one person's responses may not be comparable to another's [21].

While Nomothetic approach is a measurable and specific perspective that looks at the identification of traits and personality as a collection of characteristics. These characteristics are ones that can be described, identified and measured and therefore can be subjected to observation and tests. These are like where a characteristic (such as aggression) is studied in a large number of people who may 
be similar only in that they share this single trait [34].

The methodological and measurement-oriented approach to personality started to emerge in the beginning of the 20th century, partly as a result of psychologists' efforts to follow in the footsteps of the more "exact sciences." and inspired by the use of items and scales for measuring intelligence, inventories and questionnaires designed to measure particular personality characteristics started to be developed and used for personnel selection purposes [34],

Personality research in general started to recover during the 1980s when Costa \& McCrae developed the Personality Inventory model (1985) using a questionnaire approach for measurement. The convergence between Costa \& McCrae's [35] research, the lexical approach, and other self rating approaches gave new support for the relevance of Tupes and Christal's (1961) five broad factors, emotional stability, extraversion, openness for experience, agreeableness, and conscientiousness. Goldberg [36] was the first to use the term "Big Five" when describing these factors in order to emphasize the abstraction and broadness of each trait and to avoid giving the impression that personality could be reduced to only five traits. Taken together, this work represents the first steps towards a joint conceptualization of the five traits, the five factor model of personality [34]. The five factor model may at a first glance seem simple, basic, and nondynamic. It should be noted, however, that the multitude of relationships amongst them contribute to an extensive complexity and that there are important differences between personality traits [24]. The five-factor model traits differ in level of abstraction; some traits are more manifest and some are more abstract. The traits also differ in character; some have a more descriptive character while some are more explanatory. Some traits are primarily expressed in the interpersonal space, while others define and affect internal processes such as thoughts and feelings like conscientiousness [24].

The traits overlap at different extents. They are related to each other in different ways, and they interact in unique and non-linear fashions when they are related to different criteria. In addition, different ways of measuring the underlying constructs (e.g. via self-reports and interviews) affect estimated relationships with other variables. Some aspects of this complexity become apparent when considering the core definition of each construct [24]. The constructs that explain the five factor model traits are neuroticism, extraversion, openness to experience, agreeableness and conscientiousness.

The construct of neuroticism, which is an intra-individual trait, is defined as an enduring tendency to experience negative emotional states, such as anxiety, anger, guilt, disgust, and depression. Individuals who score high on neuroticism are on average more likely than others to interpret situations as threatening or hopelessly difficult, and to respond to them in accordance with the underlying trait being anxious, moody, hostile, irritable, personally insecure, sad or even depressed. An individual with a low level of neuroticism is typically emotionally stable, calm, and relaxed, and handles stress without a problem. Measures of this trait are often reversed to represent its opposite, emotional stability, in order to ease interpretation and to better fit into non-clinical settings. Emotional stability is often pointed out as being somewhat of a driver for the other traits [24].

The inter-individual trait extraversion is defined as the degree of energy a person directs towards the outer world, including his or her social surroundings. Individuals scoring high on extraversion are characterized as being excitable, sociable, active, and talkative [35]. Overall, they display high amounts of emotional expressiveness and need social interaction and stimulation from the outer world. Individuals scoring low on extraversion are more reserved, independent, and even-tempered. Extraversion is often thought to include aspects such as warmth, empathy, and assertiveness, which would be to presume certain "character" features for their social interaction with others. The term extraversion, however, is used to refer to individuals' degree of social energy, the amount of attention they direct towards social surroundings, and their need and capacity to interact with other people [24].

The intra-individual trait of openness to experience is characterized by openness towards the person's own inner feelings and emotional states [35]. This includes the ability to differentiate between nuances of emotions, to be open to the flow of emotions, and to have a tendency to give emotional states a prominent role or for it to be a determinant of behavior. The need and search for stimulation of one's inner world of emotional experiences may be accompanied by explicit behaviors, such as engaging in physical activities, preferably new ones, or it may also involve mental activities (e.g., meditation, intellectual reasoning).

The focus for the search for stimuli, which can be directed towards the outer world or towards the inner mental world, is likely to be determined by the individual's degree of extraversion. High levels of openness to experience are typical of individuals who have an active imagination, are attentive to inner feelings, and who are intellectually curious. Individuals with low levels do not have the same need or urge for new emotional experiences. They are likely to be more conventional and conservative, and tend to settle for what is familiar and previously experienced.

The construct of agreeableness, an inter-individual trait, refers to the character of an individual's relationships. The construct includes attributes such as trust, altruism, kindness, affection, warmth and other pro-social behaviors. A high level of agreeableness corresponds to being altruistic, helpful, warm, compliant, and modest towards others. A high need for consensus as well as need for approval and popularity are characteristics that might lead to conflict avoidance and difficulties with expressing and standing by personal opinions. A low level of agreeableness, on the other hand, characterizes someone who is more reserved, independent, skeptical, and critical towards others' intentions [24]. Having such a low need for others' approval, in combination with a typical distinct and straightforward communication style, is likely to result in these individuals 
being perceived as less agreeable and somewhat antagonistic [24].

The construct of conscientiousness concerns how individuals approach to their tasks, commitments, and undertakings. The level of achievement- and performancestriving and the preferred way of accomplishing goals are included in the definition. Effectiveness, persistence, and goal-directed behaviors are typical for those high in this trait. They also tend to be organized, mindful of details, reliable, self disciplined, and self-motivated (Sofia, 2014). Others typically describe them as competent, dutiful, selfdisciplined, and well organized. Individuals with low levels are likely to have a more liberal attitude towards rules, obligations, commitments, and tasks and tend to be less selfmotivated. They are often described by others as flexible and free-spirited, but also as careless, irresponsible, lazy, impulsive, low in achievement striving and lacking in ambition [24].

Following the above explanations, this study would measure personality factor constructs using the major approaches of nomothetic and idiographic or nature and nurture, in line with the popular opinions of McCrae \& Costa [35], as supported by Mullins [21], Alkahtani et al [33] and Sofia [34] by using adapted questionnaire approach for measurement.

\subsection{Personality and Consumer Buying Behaviour}

Consumers purchase products to reflect their personality. The type of houses, clothes, furniture, appliances, automobiles, jewelry people buy may reflect their personalities. It is seen that people of higher class tend to purchase highly priced products. Marketers therefore develop their products and advertising and promotional campaigns keeping in mind the personality types of their target customers [8].

Matzler, et al [15], Ade et al [16], and Sarker et al [8] demonstrated empirically the relationship between personality and consumer behaviour. For instance personality factor of extraversion was directly related to positive consumption emotions and neuroticism predicted negative consumption-based emotions. Matzler et al [15] not only confirm that emotions play a crucial role in satisfaction, but also reveal their dependence on consumers' individual predisposition. Similarly Kamran [37] established agreeableness factor as the single predictor of customer satisfaction. Today people are very concerned about their image and status in the society which is a direct outcome of their material prosperity. The profession or the occupation a person is in again has an impact on his/her personality and the products they consume. The status of a person is projected through various symbols like the dressing, accessories and possessions. Our life styles are reflected in our personalities and self concepts, same is the case with any consumer. A life-style is made up of a person's mode of living as identified by his or her activities, interest and opinions [24].

Like the social class the human life cycle can have a significant impact on personality and consumer behavior. The life cycle is an orderly series of stages in which consumer attitude and behavioral tendencies evolve and occur because of developing maturity, experience, income, and status., for example the improvement in the purchasing power of average civil servant in Nigeria since the democratic dispensation. Take home pay of Nigerian workers relatively take them home, and has increase their buying behavior to a greater height ceteris paribus [24].

Marketers often define their target market in terms of the consumer's present lifecycle stage, and their interest in the personality is based on the assumption that, in spite of their uniqueness as individuals, members of groups and aggregates may possess a given trait or type common with each other. Thus, personality influences consumer behavior through inducing; consumer satisfaction, self concept, social class, life style and life cycle [24]. But, Mehmet [18] criticize the idea linking personality in all purchase decisions or buying behaviours. He argued that it is wrong to generalize personality influence, because not all goods and services take cognizance of personality factors in patronage. Thus, Mehmet [18] focused his study on experiential goods and services. He argued that because the theory of hedonism is the underlining influence on experiential products, the quest for pleasure, happiness and excitement which hedonism stands for has a lot to do with personality.

We support the argument of Mehmet [18], hence we were selective in the personality factors we apply, because the personality factors that influences consumer behavior among the Igbos may not be the same with people from other regions or countries.

\subsection{Empirical Studies}

Several researches have been conducted on the impact and influences of personality factors and traits on consumer buying behavior. Each of these researchers employed some form of personality factor peculiar to his or her focus region and product or services, and established a relationship, either partial or full between those factors and consumer buying behaviour of those regions and product. Such as Tan, Foo, and Kwek [14], Ranjbarian and Kia [17], Mehmet [18], Johari and Hee [19]; Sarker etal [8], and Murat [11]. For instance Tan etal [14] chose the personality factor of 'Agreeableness' and established a relationship between that and consumer buying behavior in Singapore. Ranjbarian and Kia [17] study focused on the influence of five major personality traits (Big Five) on size of consumer's consideration set. The product involvement also was considered as a moderating variable in this relation. The results indicated that within the studied population, the Big Five has no significant effect on consideration set size. But cognitive dimension of product involvement was positive and direct relation with consideration set size. Mehmet [18], using the big five personality trait established a relationship between them and experiential purchasing in Norway region. Johari and Hee [19], also using the big five personality traits based on multiple regression analysis established a 
relationship between them and Malaysian health service consumers. While Murat [11] using the Big five personality factors established a relationship between four of them and consumption of Cell phone in Nigde region of Turkey. But Sarker etal [8] lifted these efforts to a higher level by choosing nine personality factors both from Neo-Freudian and traits theory and established relationships both full and partial relationship between them and consumer buying behaviours in Khuna region of Bangladesh.

After reviewing the empirical works and studies of other authors and scholars available to us presently, we could establish that;

I The major gap in the study of personality and consumer behavior is the differences in the focused region or people, product and services under study.

II All the authors and scholars whose works were reviewed applied their personality variables based on their personal knowledge of those regions. To the best of our knowledge, there is no existing work on the impact of personality factor on consumer buying behavior towards textile materials in South Eastern Nigeria.

There is a gap in existing literature, and it is this gap in existing research literature we want to fill.

\subsection{Theoretical Framework}

The study reviewed some related theories of personality and consumer behavior in order to establish a linkage between them and buying behavior of Igbos towards textile materials. They include psychoanalytic theory of personality, Neo-freudian theory of personality, Trait theory of personality, Economic Man theory of consumer behavior, Psychodynamic theory of consumer behavior, and Behaviourist theory. But, we emphasize here that the theoretical framework upon which the study was based are Neo-Freudian theory and Trait theory [8]. Neo-Freudian theory believes that social relationships are fundamental to the formation and development of personality. For instance, Alfred Adler viewed human beings as seeking to attain various rational goals which he called style of life. He also placed much emphasis on the individual efforts to overcome feelings of inferiority e.g. by striving for superiority. The term Neo- Freudian has both been used to describe those who left the psychoanalytic society and formed their own schools of thought. These new theories, however, hold many of the same underlying beliefs of psychoanalysis, most importantly the view of the unconscious as an important drive in human emotions, cognitions, and behaviors. According to Sullivan in Murat [11] and Sarker et al [8], people continuously attempt to establish significant and rewarding relationships with others. He was particularly concerned with the individual effort to reduce tensions, such as anxiety. Many marketers use some of these neo-Freudian theories intuitively. For example, marketers who position their products or services as providing an opportunity to belong or to be appreciated by others in a group or social setting would seem to be guided by characterization of the detached individual [24].

Trait theory represents a quantitative approach to the study of personality. This theory postulates that an individual's personality is composed of definite predisposition attributes called traits. A trait is more specifically defined as any distinguishable, relatively enduring way in which one individual differs from another. In trait theory personality typically is described as having one or more such characteristics as compulsiveness, ambitiousness, gregariousness, dogmatism, authoritarianism, ethnocentrism, introversion, extroversion, aggressiveness and competitiveness. Trait researchers have found that it is generally more realistic to expect personality to be linked to how customers make their choices and to the purchase or consumption of a broad product category rather than a specific brand [24].

The psychodynamic tradition within psychology is widely attributed to the work of Sigmund Freud (1856-1939) (Stewart 1994). This view posits that behaviour is subject to biological influence through 'instinctive forces' or 'drives' which act outside of conscious thought. While Freud identified three facets of the psyche, namely the Id, the Ego and the Superego, other theorists working within this tradition, most notably Jung, identified different drives.

The key tenet of the psychodynamic approach is that behaviour is determined by biological drives, rather than individual cognition, or environmental stimuli. The way one was brought up influences his or her consumption attitude, thus, relating to our earlier trait theories of personality.

Essentially Behaviourism is a family of philosophies stating that behaviour is explained by external events, and that all things that organisms do, including actions, thoughts and feelings can be regarded as behaviours [24]. The causation of behaviour is attributed to factors external to the individual. The most influential proponents of the behavioural approach were Ivan Pavlov (1849-1936) who investigated classical conditioning, John Watson (1878-1958) who rejected introspective methods and Burrhus Skinner (1904-1990) who developed operant conditioning. Each of these developments relied heavily on logical positivism purporting that objective and empirical methods used in the physical sciences can be applied to the study of consumer behavior [24].

The outcome of this blend of theories that constitute the fulcrum of our study is the establishment of the linkages between them and consumer buying behavior of textile materials in South Eastern Nigeria. Because Igbos buy and wear materials that suit their personality, culture and social status, as a result of biological influences or drives and the environmental influences.

\section{Methodology}

This study has been designed in line with survey research using data collected from both primary and secondary sources. The secondary sources comprises of mainly text books, journals and periodicals, while primary source is only 
from questionnaires.

The population of this study comprise of all the Igbo consumers of textile materials in the South Eastern Nigeria. The total population of South Eastern Nigeria is 16,395,555 according to Nigerian Population Commission (NPC). This population is made up of all individuals - male and females, workers in public and private organisations, Business men, Students and traders in the five States of Abia, Anambra, Ebonyi, Enugu, and Imo.

Since every member of the population can not be reached, this study selected 500 respondents using judgmental sampling, whereby the researcher uses his/her value judgment to select respondents from the population whose opinions the researcher feels relevant to make a valuable decision. [24]

The sample design adopted was is in line with Smith \& Albaum [24] equation for a very large population size:.

The constant values needed are the z-scores for the most common confidence levels: a) $90 \%-Z$ score $=1.645$; b) $95 \%-Z$ score $=1.96 ;$ c) $99 \%-Z$ score $=2.326$

With the assumption of the confident level of $95 \%$; Standard deviation of 0.5 ; Margin of error (confidence interval $)$ of $\pm 5 \%=(Z \text { score })^{2} \mathrm{x} \quad \operatorname{StdDev}^{*}(1-\mathrm{StdDev})$ (margin of error) $^{2}$

Required sample size $=\left\{(1.96)^{2} \times .5(.5)\right\} /(.05)^{2}=(3.8416$ $\mathrm{x} .25) / .0025=0.9604 / .0025=384.16=385$ respondents are needed

The required sample size is 385 . However we increased it to 500 by adding extra $30 \%$, because according to Isreal (1992) $10 \%$ to $30 \%$ could be added as addition sample to make up for some that may not be returned valid. Thus, $30 \%$ of $385=115+385=500$.

The structured questionnaires were designed in line with the shorter version of Big five inventory (BFI) model, which have been shown to be more justifiable in personality research [24]. The model uses three questions for each personality trait that exhibit a strong convergent validity. The respondents were asked to indicate to what extent they agreed with a set of statements. Likert scale was applied in ranking responses. Thus, 500 questionnaires were administered in all the major cities and selected towns and villages in each of the senatorial zones of each state to give an all encompassing coverage. This is because most of the senatorial zones have homogeneous characteristics like culture and dressing styles.

Multiple regression analysis was applied to analyse the cumulative effect of personality on consumer buying behavior of textile materials. The multiple regression analysis tells us how well a set of variables is able to predict a particular outcome. It is the best approach where we have a set of variables in various personality factors and want to know how much each, like social character, compliance, and aggressiveness explain as a group [24].

Thus; $\mathrm{Y}=\mathrm{X}+\beta 1 X 1+\beta 2 X 2+\beta 3 X 3+\beta 4 X 4---+$ $\beta n X n$.

Where, $\beta=$ Coefficient of the varriables

$\mathrm{X}=$ Variables
$\mathrm{X} 1=$ Social character, $\mathrm{X} 2=$ Compliant; $\mathrm{X} 3=$ Aggressiveness; X4= Ethnocentrism; X5= Dogmatism.

The dependent variables are the eleven Consumer oriented behaviours shown in the questionnaire and item statistics reliability test table.

Instrument validity and reliability

The constructs of the independent variable and dependent variable were validated through reliability/item statistics test analysis. A construct represents a collection of behaviors that are associated in a meaningful way to create an image or an idea invented for a research purpose [24]. A pilot study was conducted, and the items were rated on a Likert scale. The constructs of the independent variable and dependent variable were validated through reliability test analysis during the pilot study also.

Consumers Buying behaviours Reliability test

Scale: ALL VARIABLES

Table 1. Reliability test result for consumer buying behavior variables.

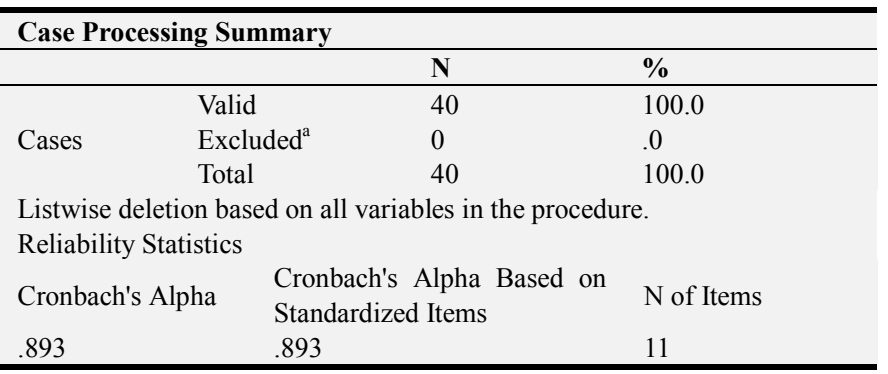

Personality Factors related behaviours Reliability test Scale: ALL VARIABLES

Table 2. Reliability test result for personality factors related variables.

\begin{tabular}{llll}
\hline \multicolumn{2}{l}{ Case Processing Summary } & & $\mathbf{\%}$ \\
\hline \multirow{3}{*}{ Cases } & Valid & 40 & 100.0 \\
& Excluded $^{\text {a }}$ & 0 & .0 \\
\multirow{2}{*}{ a. Listwise deletion based on all variables in the procedure. } \\
\hline
\end{tabular}

Table 3. Principal component Analysis test Result.

\begin{tabular}{lll}
\hline Reliability Statistics & & \\
\hline Cronbach's Alpha & $\begin{array}{l}\text { Cronbach's Alpha Based } \\
\text { on Standardized Items }\end{array}$ & N of Items \\
.697 & .709 & 20 \\
\hline
\end{tabular}

Reliability of the constructs was conducted to determine the suitability and internal consistency of the measures used. The cutoff point for measuring reliability in the personality study must be at least 0.70 or greater as suggested by Johari \& Hee (2013). Since all our Cronbach's Alpha Based Standardized Items values of the constructs were above 0.70 , the measuring items of each construct were deemed reliable.

\section{Results / Findings}

Results of the multiple regression analysis revealed that there is significant impact of personality factors on consumer buying behaviour of textile materials in South Eastern 
Nigeria. Reason being that the calculated $\mathrm{p}$ value of 0.000 was found to be lower than the 0.05 alpha level of significance with the F calculated value of 28.662 .

The strength of the impact of the personality factors on consumer buying behaviour is strong because the calculated $R$ value of 0.523 and the $R$ square value of 0.474 and the Adjusted R square value of 0.464 were each higher than the critical $R$ value of 0.440 . However on individual analysis it was found out that while there is significant impact on, social character, compliance, ethnocentrism and aggressiveness, it was found out that dogmatism has no significant impact on consumer buying behaviour towards textile materials in south eastern Nigeria. This implies that personality factors significantly affect consumer buying behavior. Therefore the null hypotheses which state that 'there is no significant effects of Social character, compliance, aggressiveness, and ethnocentrism on consumer buying behavior of textiles materials in South Eastern Nigeria, is hereby rejected.

Table 4. Multiple Regression showing the cumulative impact of personality factors on consumers buying behavior towards textile materials in South Eastern Nigeria.

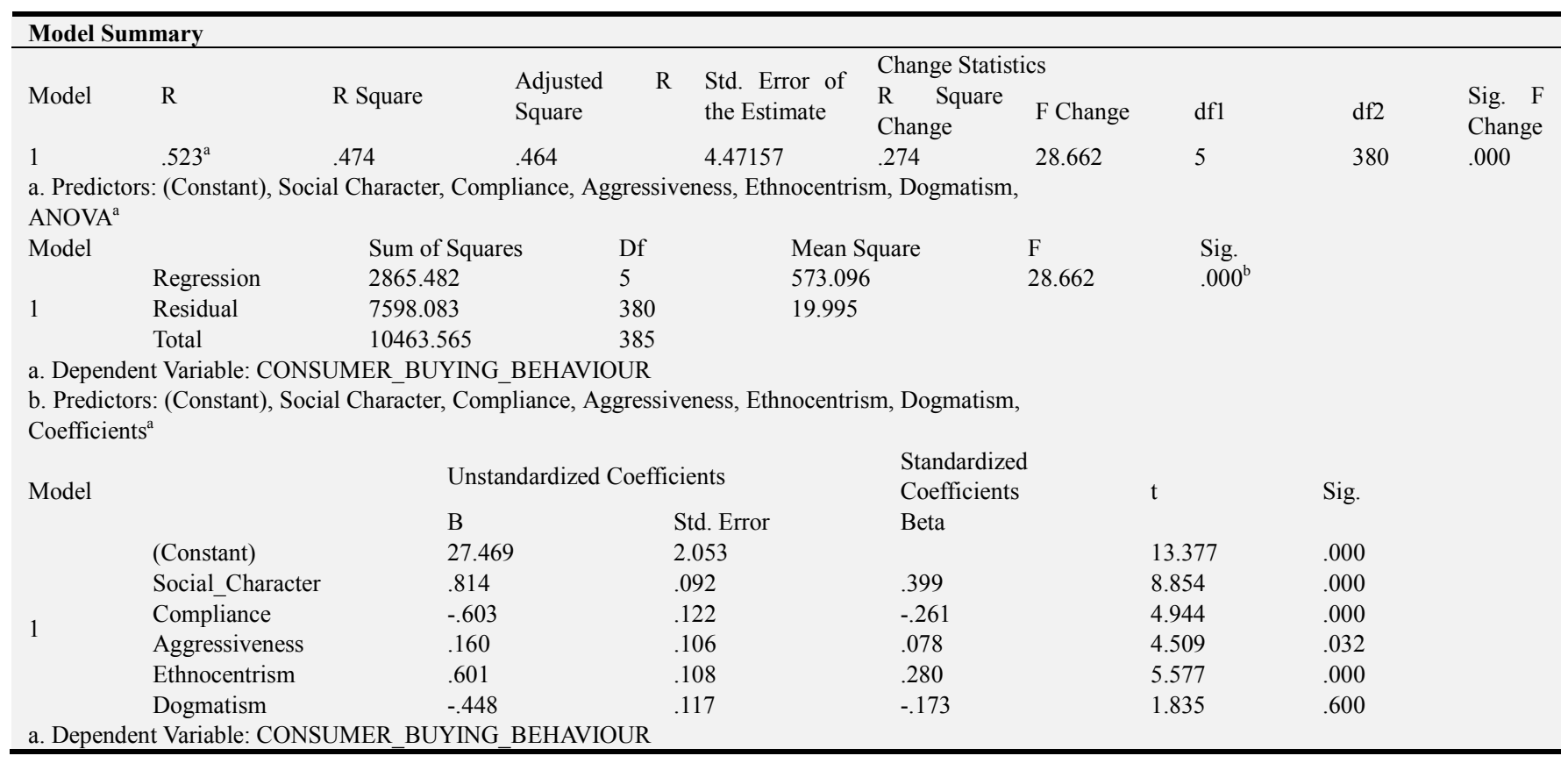

\section{Discussion of Major Findings}

The purpose of this study was to assess the impact of Personality Factors on Consumer Buying Behaviour towards Textile Materials in South Eastern Nigeria. To achieve this, five research objectives, five research questions and five research hypotheses were raised.

Objective 1; Identify whether there is a significant effect of social character on consumer's buying behavior of textile materials in South Eastern Nigeria. The objective was achieved because the findings revealed that there is a significant effect of social character on consumer buying behaviour of textile materials in South Eastern Nigeria. This is because the consumers benefits from others advice in purchasing, and many of the consumers belong to age grades, purchase and belief is alright, also they buy textiles their age grades wears. It is also in line with findings of Murat [11] and Sarker et al [8] cited in literature review.

Objective 2; Examine if there is a significant effect of compliance on consumer's buying behaviour of textile materials in South Eastern Nigeria. The objective was achieved because the findings indicated that there is a significant effect of compliance on consumer buying behaviour of textile materials in the South Eastern Nigeria, because the consumers like being with their friends or moves towards others, negotiate prior to purchase, consult and mostly share opinions before any buying. It is also in line with findings of Murat [11] and Sarker et al [8] cited in literature review

Objective 3; Determine whether there is a significant effect of aggressiveness on consumer's buying behavior of textile materials in South Eastern Nigeria. The objective was achieved because the findings showed that there is a significant effect of aggressiveness on consumer buying behaviour of textile materials in the South Eastern Nigeria, because consumer's prestige influences their buying decisions; recognize their counterparts as competitors and they desire to excel in all they do. It is in line with the opinion of Sarker et al [8] cited in literature.

Objective 4; Assess whether there is a significant effect of ethnocentrism on consumer's buying behaviour of textile materials in South Eastern Nigeria. The objective was achieved because the findings indicated that there is a significant effect of ethnocentrism on consumer buying behaviour of textile materials in the South Eastern Nigeria, because the consumers belief that buying home products keeps the country working better, thus there should be higher 
tax on foreign products/textiles to enter home country; prefer importing of unavailable products only. This is in line with the opinion of Schiffman \& Kanuk [10] and Sarker et al [8] quoted in literature review.

Objective 5; Investigate if there is any significant effect of dogmatism and consumer's buying behaviour of textile materials in South Eastern Nigeria. The objective was achieved because the findings proved that there is no significant effect of dogmatism and consumer buying behaviour of textile materials in South Eastern Nigeria, because the consumers does not buy similar product/textiles all through, but accept the introduction of new textile products by firms. This findings differs from the outcome of the study of Sarker et al [8] cited in literature, may be due to the peculiar nature of textile material.

\section{Conclusion}

This study was conducted in the south eastern region of Nigeria to find out the factors of personality at dominance in influencing the buying behaviours of mostly Igbo speaking people of this region towards textile materials. To achieve the main objective a total of 386 respondents including their responses on the 11 items on consumer related buying behavior and another 20 items on the personality factors of social character, compliance, aggressiveness, ethnocentrism and dogmatism were carefully selected from the study area consisting of all categories of people in order to have unbiased outcome. Personality is therefore a highly relevant explanatory concept for the examination of consumption of goods and services in South Eastern Nigeria.

Limitations

There were some limitations in this study which may need to be addressed in future research. One of the limitations of the study is the low response rate, which unfortunately lessens the generalisability of the findings to the entire population of Igbo people. Secondly, the independent variables of this research were confined to personality factors only. Future study may consider other individual factors such as culture, social class, and education as the predicting and influencing variables of personality. Another issue that can be considered a limitation is the use of only 11 items for capturing the four personality traits and factors. This author thus suggests that scholars in future research adopt an extended version of the 'Big Five' model or develop new model.

\section{Recommendations}

Based on the findings of this research work, we wish to make the following recommendations which might be effective in reducing personality problems in consumer buying behavior of textile materials in South Eastern Nigeria.

I Considering the social character nature of Igbo people in South Eastern Nigeria, marketers should target their strategies on convincing the social influencers within any age grade, as their purchase decisions will go a long way in commanding the brand acceptance of each product.

II Higher compliance consumers in the South Eastern Nigeria tend to be more receptive and moved towards others hence marketers of textile materials should consider the use of celebrities to promote their products, especially during festivals by designing textile materials that will add glamour to such festivals.

IIISince consumers in south eastern Nigeria are aggressive in personality, as their prestige influences their buying decision of textile materials, thus marketers should aim advertisements towards boosting their ego and esteem, by perhaps linking a particular brand to show a sign of success or wealth.

IVMarketers should make more efforts and research towards understanding the ethnography of people of this region, and based on their product and services preferences, provide them with the suitable services befitting their personality, since they are ethnocentric.

$\mathrm{V}$ The, producers and marketers of textile materials in South Eastern Nigeria should design them in line with the personality factors identified, as this will go a long way in the patronage of made-in- Nigeria textiles and contribute to economic growth and development of Nigeria

\section{References}

[1] Kotler, P, Keller, L (2006) "Marketing Management" McGraw Hill Inc, New Delhi.

[2] Keng, C. Tran. V. D, Leeti. T. M (2013) "Relationships among Brand Experience, Brand Personality, And Customer Experiential Value" Journal of Contemporary Management Research. 9 (3) 247-262.

[3] Pinki, R (2014) "Factors influencing consumer behavior", International Journal of Research and Academic Review; 2(9) 52-61.

[4] Haliru, M (2013) "Culture and Values in Consumer Behaviour: The Nigerian Experience" International Journal of Arts and Commerce 2 (10), 102-113.

[5] Yakup, D (2014) 'The Impact of Psychological Factors on Consumer Buying Behavior and an Empirical Application in Turkey' Asian Social Science Journal; 10 (6) 194-204.

[6] Ali. K, Babak J. N, Seied R. H (2014) "The influence of personality traits of customers on their loyalty A case study Of private banks of Kermanshah"; International Research Journal of Applied and Basic Sciences, 8 (2): 241-245.

[7] Sagini T M, Haridas. R. (2014) "Personality - its impact on impulse buying behaviour among the retail customers in Kochin city" IOSR Journal of Business and Management, 16 (IV) 48-55.

[8] Sarker. S, Bose. T. K. Palit. M, Haque. E, (2013) "Influence of personality in buying consumer goods-a comparative study between neo-Freudian theories and trait theory based on Khulna region" International Journal of Business and Economics Research 2 (3) 41-58. 
[9] Onu, A. J. C, Akhemien, E, Orji, M. G (2014): “Assessing the Relationship between Personality factors and Consumer behavior in South Eastern Nigeria". International Journal for Business and Social Sciences, 5 11(1), 231-242.

[10] Schiffman, L. G. Kanuk. L, (2008) "Consumer Behavior” Prentice Hall, NY.

[11] Murat, A. (2011) 'Predicting Consumers Behavioral Intentions with Perceptions of Brand Personality: A Study in Cell Phone Markets'; International Journal of Business and Management 6(6) $102-113$

[12] Khan, M. (2007) "Consumer and Advertising" New Age International Publishers, New Delhi.

[13] Awa, H. O, Kalu, S. E, Awara N. F, (2010) “An Empirical Investigation of Cultural Factors and Consumption Patterns Correlates in the South-South Geopolitical Zone of Nigeria", International Journal of Marketing Studies 2, (1) 185-199.

[14] Tan, H. H, Foo M. D, Kwek, M. H (2004) 'The effects of Customer Personality traits on the display of Positive Emotions', Academy of Management Journal 47(2) 287-296.

[15] Matzler K, Faullant R, Renzl B, Leiter V (2005) "The relationship between personality traits (extraversion and neuroticism) emotions and customer self-satisfaction," Innovative Marketing Journal, 1(2): 32-39.

[16] Ade J. P, Costas V, Garcia-Godos, B, Iglesias J, Llerena L, Ramic A, Carraher SM, Pratt Y, Brown N, Woodside L (2010). "The Big Five Personality and Their Impact On Customer Services in Russia, China, Albania, and The USA" Proceedings Academy of Marketing Studies.. 15(1):1-7, New Orleans.

[17] Ranjbarian, M. Kia, N (2010). "The Influence of Personality Traits on Consideration Set Size". European Journal of Social Sciences, 15 (2), 124-136.

[18] Mehmet, M (2012) "Personality effects on experiential consumption" Elsevier Journal, Norway, (52) 94-98.

[19] Johari, H. Hee. O. C (2013) "Personality Traits and CustomerOriented Behavior in the Health Tourism Hospitals in Malaysia" International Journal of Trade, Economics and Finance, 4 (4) 213-218.

[20] Ghorbani, H, \& Mousavi, S. M (2014) "The study impact of consumer personality traits on brand personality and brand loyalty (Case Study: product group of Isfahan Iran Khodro)". International Journal of Academic Research in Business and Social Sciences 4, (1) 371-385.

[21] Mullins, J. L (2010) "Management and Organisational Behaviour' Ninth edition". Prentice Hall Financial Times, New York.

[22] Pinki, R (2014) "Factors influencing consumer behavior", International Journal of Research and Academic Review; 2(9) $52-61$
[23] Stewart, J., (1994) 'The psychology of decision making'. In: D. Jennings and S. Wattam, eds. Decision Making: an Integrated Approach. London: Pitman.

[24] Orji, M. G (2015) "Impact of personality factors on Consumer Buying behavior towards textile materials in South Eastern Nigeria" PhD Thesis, Department of Business Administration, Ahmadu Bello University, Zaria, Nigeria.

[25] Farahani M. N. (2007). "Personality Psychology, Utilization and Researching, Msc Thesis"; Tehran, Tarbit Mooalem University.

[26] Shimai, S., and Otake, K. (2002) 'An analysis of the relationship between aggressiveness and personality traits of children', Japanese Journal of Psychology (73) 358- 36.

[27] Cetin N. G, Beceren, E. (2007). "Leader Personality: Gandhi”, Süleyman Demirel Üniversitesi Sosya Journal Publications, 3, (5), 110-132.

[28] Kotler, P, Keller, L (2006) "Marketing Management" McGraw Hill Inc, New Delhi.

[29] Dursun. T. (2009) "Process to Create a Brand Personality and a Study on Brand Personality" Marmara İletişim Press, İstanbul.

[30] Mishra P. Detta. B (2008). 'Consanguinity between Consumer and Brand Personality: A Review'. The Icfai University Journal of Consumer Behavior, III (3) 7-14.

[31] Bray, J. (2013) "Consumer Behaviourial Theory; Approaches and Models" Coazy press, London.

[32] Feldman, R. S, (2000) "Essentials of Understanding Psycholog' fourth edition", M Graw Hill Higher Education Publishers, New Delhi.

[33] Alkahtani, A. H Abu-Jarad. I. Sulaiman, M \& Nikbin, D (2011) "The Impact of Personality and Leadership Styles on Leading Change Capability of Malaysian Managers", Australian Journal of Business and Management Research 1 (2), 70-83.

[34] Sofia, C. J (2014) 'Utilizing Research in the Practice of Personnel Selection, General mental ability, Personality, and job Performance'. Published PhD Thesis Printcenter US-AB, Press, Stockholm.

[35] McCrae, R. R., \& Costa, P. T. (2008) "The five-factor theory of personality. In O. P. John, R. W. Robins, \& L. A. Pervin (Eds.), Handbook of personality". Theory and research (159181). New York, NY: Guilford press.

[36] Goldberg, L. R. (1981) "Language and individual differences: The search for universals in Personality lexicons. In L. Wheeler (Ed.)" Review of personality and social psychology Beverly Hills, CA: Sage.

[37] Kamran, S. (2012) "Personality influences on customer satisfaction" African Journal of Business Management. 6(11), 413-414. 